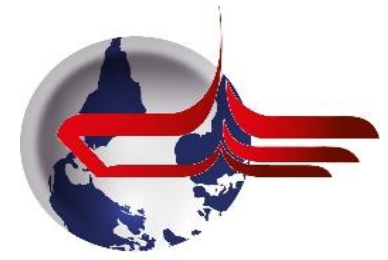

Turkish Journal of Educational Studies, 6 (1) Ocak $2019 \quad$ Research Article / Araştırma Makalesi

Article İnfo/Makale Bilgisi

Received/Geliş: 10 Kasım 2018

Accepted/Kabul: 9 Ocak 2019

\title{
Öğretmen Adaylarına Göre Öğretim Teknolojileri Ve Materyal Tasarım Dersi*
}

\begin{abstract}
Ayşenur KULOĞLU**
$\ddot{\mathbf{O z}}$

$\mathrm{Bu}$ çalışmanın amacı öğretmen adaylarının "öğretim teknolojileri ve materyal tasarım dersi"ne ilişkin görüşleri belirlemek ve bu derste karşılaşıtıları durumları belirlemektir. Araştırmanın çalışma grubunu 2017-2018 öğretim yılında Fırat üniversitesi eğitim fakültesi Sınıf öğretmenliği, Türkçe öğretmenliği ve Okul öncesi öğretmenliğinde öğrenim gören toplam 75 öğretmen adayı oluşturmaktadır. Araştırmada nitel araştırma yöntemi kullanılmıştır. Veriler araştırmacı tarafından hazırlanan yarı yapılandırılmış görüş̧me formu ile toplanmıştır. Elde edilen verilerde içerik analizi ile çözümlenmiştir. Çalışma sonuçlarına bakıldığında; öğretmen adaylarının büyük bir çoğunluğu öncelikli olarak hazırlanacak materyallerin öğrencilerin dikkatini çekmesi gerektiğini, materyal hazırlamak için alınacak malzemelerin fiyatlarının uygun olmasını, hazırlanmış olan materyallerin dayanıklı olmasını en fazla dile getirilen görüşler arasındadır. Ayrıca öğretmen adaylarının materyal hazırlarken grup oluşturması veya bireysel olarak çalışma isteği öğrenci ve öğretim üyesinin ortak kararı ile verilmedir. Yapılan materyal daha sonra tekrardan kullanılabilmesi için gerekli izinler alındıktan sonra okullara hediye edilebilir. Ayrıca Öğretmen adaylarının derse yönelik motivasyonları artırmak için yapmış oldukları materyaller dönem sonunda sergilenebilir.
\end{abstract}

Anahtar Kelimeler: Öğretim Materyalleri, Öğretim Teknolojileri, Nitel Araştırma.

Instructional Technology and Material Design Course According to Teacher Candidates

\begin{abstract}
The aim of this study is to determine the opinions of the teacher candidates about the "instructional technology and material design course" and the situations/cases/problems they meet/face in this course. The study group of this research consists of a total of 75 teacher candidates who are studying in the primary school teaching, Turkish teaching and pre-school teaching departments in the faculty of education at the Firat University in the academic year of 2017-2018. Qualitative research method is used in the research. The data were collected through a semistructured interview form prepared by the researcher. The obtained data were analyzed by content analysis. According the studuy results; the vast majority of pre-service teachers mostly mentioned that the materials to be prepared should first attract students' attention, the prices of the materials to be bought to prepare materials should be affordable and the materials prepared should be durable. Furthermore, pre-service teachers' request to create a group or to work individually while preparing material should be determined by the joint decision of the student and the instructor. The material designed can be presented to schools so that it can be used again, after obtaining the necessary permissions. Moreover, the materials designed by pre-service teachers can be exhibited at the end of the term to increase their motivation for the course.
\end{abstract}

Keywords: InstructionalMaterials, Instructional Technologies, QualitativeResearch.

*Bu çalışma 11-14 Nisan 2018 tarihinde 17.Uluslararası Sınıf Öğretmenliği Sempozyumunda sunulmuştur. 
** Dr.Öğretim Üyesi Frrat Üniversitesi Eğitim Fakültesi, Eğitim Bilimleri Bölümü, 23119 Elazı̆̆. adonder@firat.edu.tr

\section{Giriş}

Öğrenme ve öğretim süreçlerinde bireyler çeşitli bilgi aktarım süreçlerinden geçer. Bu aktarım süreçlerinin etkin ve kalıcı öğrenmelerin sağlanması için bireylerin işitsel, görsel ve duyusal olarak hitap edilmelidir. Bu nedenle Öğretme ve öğretim sürecinde ise öğrencilerin birtakım öğretim materyallerine ihtiyaç duyulmaktadır.

Öğretim materyalleri öncelikli olarak, eğitimde kullanılacak her türlü araç gereçleri ve teknolojinin; öğretme ve öğretme sürecine hitap ederek, öğrencilerin bireysel ihtiyacını karşılamalı ve öğrencilerin dikkatini çekerek, somut kavramları somutlaştırarak, öğrenmeleri kalıcı hale getirerek öğrenme ve öğretme ortamlarının önemli unsurları olarak kabul edilmektedir (Heinich ve diğ., 2002; Yalın, 2002). Ayrıca öğretimde materyal kullanmak bireylerin derse odaklanmasını, kalıcı öğrenme çevreleri oluşturmasını sağlar. Öğrencilerin derse odaklanmasını sağlayarak, öğrencilere hareketlilik getirir. Öğrenmede ki zorluğu ortadan kaldırır. Öğrenme sürecinde işitsel, kokusal, dokunsal, tatsal ve görsel ne kadar fazla duyu organa hitap ederse o kadar kalıcı ve etkili öğrenme durumları ortaya çıkar (Çelik,2010). Aynı zamanda öğretim materyalleri kullanılarak süre olarak ve kelimeden tasarruf edilir, bilgilerin kafamızda şekil oluşturmasına yarar, daha kolay öğrenmeleri sağlar, öğrencilerin derste aktif olmasını sağlar, odaklanma sorununu ortadan kaldırır, öğretim daha anlaşı1ır hale gelir ve ders hakkında daha çok alıştırma yapmamızı sağlar (Halis, 2002).

Öğretmen-öğrenme sürecini sistem olarak alınırsa, süreçteki tüm unsurlar birlikte uyumlu biçimde el alınarak düzenlenmesi gerekmektedir. Öğretmen-öğretme sürecinde en önemli göreve sahip olan, aktif rol oynayan öğretmenlerin kısa zamanda çok daha fazla bilgiyi öğrencilere aktarabilmek için uygun eğitim ortamları hazırlamaları gerekmektedir(Yalın,2002). Uygun eğitim ortamlarının oluşturulması için, yeni yöntem ve tekniklerin uygulanması, öğretimin daha kalıcı olması amacıyla görsel materyallerin kullanılmasında öğretmene büyük görev düşmektedir. Bu yüzden öğretmen, öğrencilerin öğrenme düzeylerini en üst seviyeye taşımak ve daha etkili öğrenmeler gerçekleştirmek için yeni araç-gereçleri de sürekli olarak takip etmeli, öğrenmeli ve kullanmalıdır (Akçay, Feyzioğlu ve Tüysüz, 2003; İzci, 2004).

Öğretmen eğitim- öğretim içerisinde teknoloji ve materyal kullandıkça öğrencilerin kalıcı öğrenmelerinde fayda sağlar. Materyal kullanımı dersin akıcılığını sağlayıp, öğrencilerin derse odaklanmasını etkin hale getirir. Konuları sürekli anlatım tekniğiyle kullanan öğretmenler belli bir süre sonra öğrencilerin derse katılımını sağlayamayabilir. Öğrencilere öğretim sürecinde materyal kullandıkça öğrenciler derse aktif olarak katılıp, öğrendikleri bilgileri daha zor unutabilirler. Bu durumda öğretmenlerin bireylere aktarımlarını kolaylaştırmaktadır. 
Yüksek Öğretim Kurulu 1998 yılında tüm öğretmen yetiştirme programlarında zorunlu ders haline getirilen, öğretmen kalitesini ve niteliğini artırmaya yönelik olarak öğretmenlik programlarında dahil edilmeye başlanan "Öğretim Teknolojileri ve Materyal Tasarımı" (ÖTMT) dersi eklenmiştir. Bu dersin içeriğinde "Çeşitli öğretim teknolojilerinin özellikleri, öğretim sürecindeki yeri ve kullanımı, öğretim teknolojileri yoluyla öğretim materyallerin geliştirilmesi ve çeşitli nitelikteki materyallerin değerlendirilmesi." olarak belirlenmiştir (YÖK, 1998). Eğitim fakültelerinde okutulan ders, öğretmen adaylarının araç gereçlerin öğretimdeki yerini kavrayabilmeleri, öğrenme ve öğretme sürecinde gerekli olduğu durumlarda materyal hazırlayabilmelerini, geliştirebilmelerini ve teknolojiyi kullanabilmeleri amaçlanmaktadır (Gündüz, Odabaşı, 2004). Böylece öğretmen adaylarının bu beceriler ile öğretim materyallerinden yararlanabileceklerdir. Öğretim materyalleri ayrıca eğitimin niteliğini artırır, öğrencilerin motivasyonunu artırır ve açık ve anlaşılır ortamlar hazırlayarak daha verimli çalışma ortamları sunar (Akkoyunlu, 2002). Hazırlanmış olan bazı materyaller öğretmenin yerini tutmasa da konuyu öğrencilere aktarmada yardımcı olur ve ÖTMT dersinde kazandırılan bilgi ve beceriler öğrenme ve öğretme süreçlerinin verimli olmasında öğretmenlere hizmet ederler (Şahin ve Yıldırım 2004; Tutkun ve Koç,2001; Güneş ve İskenderoğlu 2014) .

Bu çalışmanın amac1, sınıf öğretmenliği, okul öncesi öğretmenliği ve Türkçe öğretmenliğinde öğrenim gören öğretmen adaylarının ÖTMT dersine yönelik görüşlerini ortaya koymaktır. Araştırmanın öğretmen adaylarının bu derse yönelik öğretmen adaylarına ve dersin sorumlusu olan öğretim üyelerine katkıda bulunabileceği için önemli görülmektedir. Bu nedenle öğretmen adaylarının görüşlerine dayalı olarak şu sorular sorulmuştur.

- ÖTMT dersinde materyal geliştirirken nelere dikkat edilmelidir?

- ÖTMT dersinde materyal geliştirirken karşılaştığınız sorunlar nelerdir?

- ÖTMT dersinin daha verimli geçmesine yönelik önerileriniz nelerdir?

\section{Yöntem}

Öğretim teknolojileri Materyal Tasarımı dersine ilişkin öğretmen adaylarının görüşlerini belirlemek amacıyla nitel araştırma yöntemi kullanılmıştır. Nitel araştırmalar "görüşme, doküman analizi, gözlem gibi nitel veri toplama yöntemlerinin kullanıldığı, olayların doğal ortamda gerçekçi olarak ortaya konmasına yönelik nitel bir sürecin yer aldığı araştırmalardır (Yıldırım ve Şimşek 2008).

\section{1. Çalıșma Grubu}


Araştırmanın çalışma grubunu 2017-2018 öğretim yılında Fırat üniversitesi eğitim fakültesi sınıf öğretmenliği, okul öncesi öğretmenliğinde ve Türkçe öğretmenliğinde öğrenim gören öğretmen adayları oluşturmaktadır. Başlangıçta 108 öğretmen adayı olarak belirlenmiş ancak daha sonra 75 öğretmen adayı cevaplamıştır. Bu çerçevede araştırma bu öğretmen adayları grubunun görüşleriyle sinirlidir.

Öğretmen adaylarına ilişkin bilgiler Tablo’1 de verilmiştir.

\begin{tabular}{llll}
\hline Bölüm & Kadın & Erkek & Toplam \\
\hline Sınıf Öğretmenliği & 23 & 10 & 43 \\
Okul Öncesi Öğretmenliği & 23 & 2 & 25 \\
Türkçe Öğretmenliği & 13 & 4 & 17 \\
\hline
\end{tabular}

Tablo 1'de görüldüğü gibi araştırmanın çalışma grubunu 75 öğretmen adayı oluşturmaktadır. Öğretmen adaylarının 43'ü sınıf öğretmenliği, 25’i okul öncesi öğretmenliği, 17'si Türkçe öğretmenliğidir. Öğretmen adaylarının 59'u kadın, 16'si erkektir.

\subsection{Veri toplama Araçları}

$\mathrm{Bu}$ çalışmada veri toplama yöntemi olarak yarı yapılandırılmış görüşme tekniği kullanılmıştır. Bu yöntem tam yapılandırılmış görüşmeler gibi katı değildir, ayrıca yapılandırılmamış görüşmeler gibi de esnek değildir; hazırlanan görüşme formu ikisinin arasında yer almaktadır (Karasar, 2007). Araştırmacı tarafından ÖTMT dersine yönelik görüşleri belirlemek için üç tane açık uçlu soru hazırlanmıştır ve yarı yapılandırılmış görüşmek formu kullanılmıştır. Görüşme formunun iç geçerliliğini sağlamak adına dört alan uzmanına sorulup, görüşleri alınmıştır. Alan uzmanları görüşme formunda yer alan soruların anlaşılır olup olmadığını ve çalışma konusunu kapsayıp kapsamadığını belirtmişlerdir. Daha sonra alan uzmanlarının istekleri doğrultusunda gerekli düzeltmeler yapıldıktan sonra örneklem dışı tutulan sekiz öğretmen adayı ile pilot görüşme yapılmıştır. Daha sonra pilot görüşmede soruların eğitim fakültesi sınıf öğretmenliği, okul öncesi öğretmenliğinde ve Türkçe öğretmenliğinde öğrenim gören öğretmen adaylarına bu görüşme formu uygulanmıştır.

\subsection{Verilerin Analizi}

Görüşmede öğretmen adaylarına 3 soru yöneltilmiş ve yapılan görüşmeler sonucunda elde edilen veriler, içerik analizine göre değerlendirilmiştir. Bulguların analizinde frekans değerleri 36 
kullanılarak tablolaştırılmıştır. Analiz sürecinde öğretmen adaylarının görüşleri tamamen kendi görüşlerine göre oluşan kategorilere göre incelenmiştir.

\section{Bulgular}

Öğretmen adaylarının vermiş olduğu cevaplar doğrultusunda öğretim teknolojiler materyal tasarım dersine yönelik görüşleri belirlenmeye çalışılmıştır.

\section{1.ÖTMT Dersinde Materyal Geliştirirken Dikkat Edilmesi Gerekenler}

Tablo 2'de 'Öğretim Teknolojileri Ve Materyal Tasarım Dersinde Materyal Geliştirirken Nelere Dikkat Edilmelidir?’ sorusuna ilişkin öğretmen adaylarının görüşleri verilmiştir.

\begin{tabular}{ll}
\hline Kategori & F \\
\hline Materyalin, malzeme fiyatlarının uygun olması & 32 \\
Öğrencilerin Dikkatini çekebilmesi & 37 \\
Materyallerin dayanıklı olması & 26 \\
Güncellenebilir olması & 19 \\
Öğretici olması ve Eğlenceli olması & 15 \\
Daha önce yapılmamış bir materyal olması yani özgün olması & 18 \\
Basit ve güncel bilgi olması & 14 \\
Tehlikeli olmaması & 4 \\
Kolay taşınabilir olması & 13 \\
Yıkanılabilir olması & 2 \\
Birden fazla duyu organına hitap edebilmesi & 12 \\
\hline
\end{tabular}

Tablo 2'de çalışmaya katılan öğretmen adaylarının 37 'si hazırlanacak olan materyallerin öğrencilerin dikkatini çekebilmesi, 32' si malzeme fiyatlarının uygun olmasını, 26'sı materyallerin dayanıklı olmasını, 19'u materyallerin güncellenebilir olmasını, 18' i hazırlanmış olan materyallerin daha önce yapılmamış olmasını yani özgün olmasını, 15'i materyallerin öğretici olması ve eğlenceli olmasını, 14' ü Basit ve güncel bilgi olması, 13 ' ü de kolay taşınabilir olmasını, 12' si Birden fazla duyu organına hitap edebilmesini, 4' ü Tehlikeli olmamasını, 2' si hazırlanmış olan materyallerin ayrıca yıkanabilir olmasına dikkat çekmişlerdir. Öğretmen adaylarının görüşlerinden bazıları şunlardır; 
S7:"Öncelikle sağlam ve dayanıklı olması gerekir. Hazırlanacak olan materyali düşük maliyet ile çok güzel şeyler çılkabilir. İlgi çekici olmalı ki öğrenciler beğensin ve merak etsin. Ayrıca hazırlanan materyal kopya çekilmeden tamamen özgün olmalıdır."

O12: Az maliyetle elimizden geldiğince büyük işler çıkarmalıyız. Yapım aşamasında tehlikeli materyallere dikkat edilmelidir. Yanıcı ve tehlikeli materyallere dikkat edip en az şekilde kullanmaya dikkat edilmelidir. Geliştirdiğimiz materyalin özgün olmasına dikkat etmeliyiz. Stradan materyaller çocuk için sıkıcı olabilir. Yaratıcı olmalıyız ve emek harcamalıyız.

T18: Kullanılan malzemelerin evde işe yaramayan malzemelerden olması önemlidir. Yapılacak materyalin taşınabilir ve kullanışlı olmasına dikkat etmeliyiz. Hazırlanan materyal hafif bir materyal olmalıdır. Kolay taşınabilir olmasına dikkat edilmelidir.

\section{2.ÖTMT Dersinde Materyal Geliştirirken Karşılaşılan Sorunlar}

Tablo 3'de 'Öğretim Teknolojileri Ve Materyal Tasarım Dersinde Materyal Geliştirirken karşılaştığınız sorunlar nelerdir?’ sorusuna ilişkin öğretmen adaylarının görüşleri verilmiştir.

\begin{tabular}{ll}
\hline Kategori & F
\end{tabular}

Malzemelerin pahalı olması

16

Grup içindeki arkadaşlarla fikir ayrılığı

28

Öğretici materyal hazırlamada sıkıntı yaşama 9

Orjinal fikir bulamamak

Materyallerin dayanıklı olmaması

Fikirleri materyale yansitamama

Malzeme bulma sıkıntısı

Materyalin taşınmasında zorluk yaşanması

Zaman 
Tablo 3'te çalışmaya katılan öğretmen adaylarının 16'sı Malzemelerin pahalı olmasını, 21'i Grup içindeki arkadaşlarla fikir ayrılığı yaşadığını, 9'u Öğretici materyal hazırlamada sıkıntı yaşadığını, 14'i Orjinal fikir bulamamak olduğunu, 9'u Materyallerin dayanıklı olmaması, 15' i Fikirleri materyale yansıtamama, 12'si Malzeme bulma sıkıntısı, 6's1 Materyalin taşırken zorluk yaşamas1, 16's1 materyallerin hazırlanmasında zaman sıkıntısı yaşadığını belirtmişlerdir. Öğretmen adaylarının görüşlerinden bazıları şunlardır;

O2: "Materyal konusunda sıra dışı bir etkinlik bulma konusunda zorlandık. Grup ödevi olduğu için fikir ayrılıkları oldu. Çünkü birlikte toplanma konusunda, zaman ve mekan bulmakta zorlandık. Materyal geliştirirken materyalin çok büyük olması ve taşımada zorluk çekilmesi gibi zorluklarla karşılaştık. Malzeme bulmada çok fazla sıkıntı yaşadık. “

S9: Özgün olması için farklı fikirler geliştirme ve sürekli düşünmek gerekir. Bu sebeple fazla zaman aldı. büyük olan materyalin taşıması zor oldu.

T14:Farklı fikirler bulmak çok zaman aldi. Zihnimizdeki materyali gerçeğe tam olarak yansıtamadık, maddi imkanlar bazen yetersiz kaldl.

\section{3.ÖTMT Dersinin Daha verimli Geçmesine Yönelik Öneriler}

Tablo 4'de 'Öğretim teknolojileri ve materyal tasarım dersinin daha verimli olması için önerileriniz nelerdir?’ sorusuna ilişkin öğretmen adaylarının görüşleri verilmiştir.

Kategori

Uygulama yapılmasına yönelik ders olmalı 7

Teknolojik gelişmeler yakından takip edilmeli 8

Materyaller okullara gönderilmeli

Ödüllendirme 5

İsteğe bağlı olarak bireysel ödev hazırlanabilmeli 21

Atık malzemeler kullanılmalı 
Tablo 4'te çalışmaya katılan öğretmen adaylarının 7'si Uygulama yapılmasına yönelik ders olmal1, 8' i Teknolojik gelişmeler yakından takip edilmeli, 12' si Materyaller okullara gönderilmeli, 5' i çok iyi hazırlayan materyallerin ödüllendirilmesi gerektiğini, 21' i İsteğe bağlı olarak bireysel ödev hazırlanabilmeli, 18' i Atık malzemeler kullanılmalı, 23'ü de dönem sonunda sergi olmalı gerektiğini belirtmişlerdir.

S6: Atık malzemeleri geri kazandırıp bir şeyler yapılabilir. Materyali geliştirirken internette çok fazla aynı şeyle karşılaştım. Özgünlüğü sağlamak adına, bu noktada çok hassas davranılmalı. Grup yerine bireysel çalışmaların yapılması daha rahat çalışmamızı sağlayabilir. Bu sebeple bireysel çalışma olmalıdır. Her birey kendi fikrini tek ortaya koymalıdır. Böylece daha fazla fikir ve materyal olur.

O13: Yapılan materyallerin hepsi dönem sonunda bir yerde sergilenebilir ve en güzel seçilen ödev ödüllendirilebilir.

T 4: Teknolojik gelişmeler yakından takip edilmeli ve bireysel veya grup çalışmast yapmak öğrencinin isteğine bırakılmall, materyalin ekonomik olması için atık malzemelerden olmasına teşvik edilmelidir.

\section{Sonuç, Tartışma ve Öneriler}

Öğretmen adaylarının “Öğretim Teknolojileri ve Materyal tasarım” dersine ilişkin görüşlerini belirlemeye yönelik olan bu çalışmada şu sonuçlara ulaşılmıştır;

Öğretim teknolojileri ve materyal tasarım dersinde materyal geliştirirken dikkat edilmesi gerekenleri belirtmek amacıyla verilen cevaplara bakıldığında; öğretmen adaylarının büyük bir çoğunluğu öncelikli olarak hazırlanacak materyallerin öğrencilerin dikkatini çekmesi gerektiğini belirtmişlerdir. Benzer sonuçlara Örge yaşar (2014) ve Geçer (2010) çalışmasında da ulaşılmıştır.Materyal hazırlamak için alınacak malzemelerin fiyatlarının uygun olmasını, hazırlanmış olan materyallerin dayanıklı olmasını dile getirilen diğer görüşler arasındadır. Öğretmen adayları materyallerin güncellenebilir olmasını, hazırlanmış olan materyallerin daha önce yapılmamış olmasını yani özgün olmasını, materyallerin öğretici olması ve eğlenceli olmasını, basit ve güncel bilgi olması, kolay taşınabilir olmasını, birden fazla duyu organına hitap edebilmesini, materyallerin tehlikeli olmamasını, yıkanabilir olması dile getirmişlerdir.

Materyal geliştirirken öğretmen adaylarının karşılaş̧ı̆̆ı sorunlar ise; anlatımları sırasında en çok materyal bulma ile ilgili sıkıntılar yaşadıklarını, grup içinde fikir ayrılıkları yaşadıklarını, malzemelerin pahalı olmasını, fikirleri materyale yansıtamama gibi sorunlarını dile getirmişlerdir. Ayrıca öğretici materyal hazırlamada sıkıntı yaşadığını, orjinal fikir bulamamak olduğunu, materyallerin dayanıklı olmaması, malzeme bulma sıkıntısı, materyalin taşırken zorluk yaşaması, materyallerin hazırlanmasında 
zaman sıkıntısı yaşadıklarını belirtmişlerdir. Alan yazı incelendiğinde de benzer şeklide öğretmen adaylarının aynı şekilde benzer sıkıntılar yaşadıkları görülmektedir (Çevik Kılıç,Beste(2016);Özer , Tunca (2014);Örge Yaşar(2017); Özer ve Tunca (2014).

Materyal tasarımı dersinin daha verimli olması için öğretmen adaylarının önerilerine bakıldığında ise, uygulama yapılmasına yönelik ders olmasını, teknolojik gelişmeler yakından takip edilmesi gerektiğini, öğretici materyaller, gerekli izinler alındıktan sonra okullara gönderilebilir, çok iyi hazırlanan materyallerin sahiplerinin ödüllendirilmesi gerektiğini, isteğe bağlı olarak bireysel ödev hazırlanabilmeli, atık malzemelerin kullanılması gerektiğini, dönem sonunda sergi olması gerektiğini belirtmişlerdir.

Öğretim teknolojileri materyal tasarım dersinin öğretmen adaylarının ve öğretim üyelerinin birlikte işbirliği içinde olması gerekmektedir. Ayrıca dersin sorumlusu olan öğretim üyesinin dersin içeriğini ve amacını öğretmen adaylarına açık ve anlaşılır bir dille dile getirmelidir. Daha sonra öğretim üyesi ve öğretmen adaylarının hazırlanacak olan materyallerde neler olması gerektiğini, nelere dikkat edilmesi gerektiğini ortak karar vererek materyallerin taşıması gereken özellikler belirtilmedir. Ayrıca öğretmen adaylarının materyal hazırlarken grup oluşturması veya bireysel olarak çalışma isteği olanların hem öğretmen adaylarının ve hem de öğretim üyesinin ortak kararı ile verilmedir. Yapılan materyal daha sonra tekrardan kullanılabilmesi için gerekli izinler alındıktan sonra okullara hediye edilebilir. Ayrıca öğretmen adaylarının derse yönelik motivasyonları artırmak için yapmış oldukları materyaller dönem sonunda sergi düzenlenerek sergilenebilir.

\section{KAYNAKÇA}

Akçay, H.; Feyzioğlu, B. ve Tüysüz, C. (2003). Kimya Öğretiminde Bilgisayar Benzetimlerinin KullanımınınLise Öğrencilerinin Başarısına ve Tutumuna Etkisi. Kuram ve Uygulamada Eğitim Bilimleri,3(1),7-26.

Akkoyunlu, B. (2002). Educational technology in Turkey: Past, present and future. Educational Media International, 39(2), 165-173.

Corey, G. (1991). Theory and practice of counseling and psychotheraphy. Pacific Grove, CA: Brooks/Cole.

Çelik, L. (2010). Öğretim Teknolojileri ve Materyal Tasarımı.( Ed. Ö. Demirel ve E. Altun).Öğretim Materyallerinin Hazırlanması ve Seçimi (s.27-66). Ankara: Pegem Akademi Yayıncılık.

Çevik, K.. ve Beste, D., (2016), "Müzik Öğretmeni Adaylarının Öğretim Teknolojileri ve Materyal Tasarımı Dersi Hakkındaki Görüşleri”, Eğitim ve Öğretim Araştırmaları Dergisi, Cilt: 5, Sayı: 1, s. 1-8. 
Güneş G. ve İskenderoğlu Aydoğdu T.,(2014), ‘'̉lköğretim Matematik Öğretmeni Adaylarının Öğretim Teknolojileri ve Materyal Tasarımı Dersine Yönelik Yaklaşımları' Gazi Üniversitesi Eğitim Fakültesi Dergisi, Cilt: 34, Say1: 3, s. 469,488.

Gündüz, Ş. ve Odabaşı, F. (2004). Bilgi çă̆ında öğretmen adaylarının eğitiminde öğretim teknolojileri ve materyal geliştirme dersinin önemi, The Turkish Online Journal of Educational Technology, Cilt 3, Say11.

URL:http://www.tojet.net/articles/v3i1/317.pdfadresinden erişilmiştir.

Halis, İ. (2002). Öğretim Teknolojileri ve Materyal Geliştirme. Ankara: Nobel Yayıncılık.

Heinich, R.,Molenda, M., Russell, J. D. And Smaldino, S. E. (2002). Instructional media and Technologies for learning( 7th Ed.). Merrill Prentice Hall, USA.

İzci, E. (2004). Öğretimde Teknoloji. Öğretimde Planlama ve Değerlendirme. I. Bask1, Elazığ, Üniversite Kitapevi.

Karasar, N. (2007). Bilimsel Araştırma Yöntemleri, 17. Baskı, Ankara: Nobel Yayın Dağıtım.

Kolburan Geçer, A., (2010), “Teknik Öğretmen Adaylarının Öğretim Teknolojisi ve Materyal Geliştirme Dersine Yönelik Deneyimleri”, Yüzüncü Y1l Eğitim Fakültesi Dergisi, Aralık, Cilt: VII, Sayı: II, s. 1-25.

Ong, W. J. (2002). Orality andl iteracy: The technologizing of the word (2nd ed.). New York: Routledge.

Örge Yaşar, F., (2014), “Nitel Bir Araştırma: Türkçe Dersinde Beceri Eğitimi”, Turkish Studies- International Periodical For The Languages, Literature and History of Turkish or Turkic, Volume 9/6, Spring, p. 865-886.

Özer, Ö. Ve Tunca, N., (2014), “Öğretmen Adaylarının Materyal Hazırlama ve Kullanmaya Yönelik Görüşleri”, Route Educational and Social Science Journal, Volume 1(3), s.214-229.

Örge Yaşar, F., (2017),Pedagojik formasyon eğitimi sertifika programı ögrencilerinin ögretim teknolojileri ve materyal tasarımı dersine yönelik görüşleri: nitel bir araştırma.Akademik Sosyal Araştırmalar Dergisi, kasım, Say1: 58, s. 165-182.

Özer, Ö. ve Tunca, N. (2014). Öğretmen adaylarının materyal hazırlama ve kullanmaya yönelik görüşleri,

Route

EducationalandSocialScienceJournal, Volume 1(3).

URL:http://www.ressjournal.com/Makaleler/1062232670_16\%20Nihal\%20Tunca.pdfadresinden erişilmiştir. 
Şahin, T. ve S. Yıldırım (1999). Öğretim teknolojileri ve materyal geliştirme, Ankara: Anı Yayınevi.

Tutkun, Ö. F. ve Koç, M. (2001). Öğretim Teknolojileri ve Materyal Geliştirme Dersinin hedeflerine ulaşma derecesi. Uluslararası Eğitim Teknolojileri Sempozyumu ve Fuarı, 28-30 Kasım, Sakarya Üniversitesi, Sakarya.

Yalın, H.İ. (2002). Öğretim teknolojileri ve materyal geliştirme. Ankara: Nobel Yayınları.

Yıldırım, A. ve Şimşek, H., (2008), Sosyal Bilimlerde Nitel Araştırma Yöntemleri,6. Baskı, Ankara, Seçkin Yayıncılık.

YÖK (1998), Eğitim Fakültesi Öğretmen Yetiştirme Lisans Programlarl, Yüksek Öğretim Kurulu Başkanlı̆̆ı, Mart 1998, Ankara.

\section{Extended Abstract}

Teachers provide benefits for the permanent learning of students as they use technology and material within education and training. The use of materials ensures the smoothness of the course and activates students to focus on the course. Teachers who use the subjects with continuous lecturing technique may not ensure students' participation in lesson after a certain time. As they use materials for students in the teaching process, students can actively participate in the lesson and forget the information they learn more difficultly. This facilitates the transfer of teachers to individuals. The aim of this study was to reveal the opinions of pre-service teachers studying in the departments of classroom teaching, preschool teaching and Turkish language teaching on ITMD course. The qualitative research method was used to determine their opinions about the Instructional Technologies Material Design course. Pre-service teachers studying in the departments of classroom teaching, preschool teaching and Turkish language teaching in Firat University Faculty of Education during the 2017-2018 academic year constituted the study group of the research. Initially, 108 students were determined, but then 75 students answered. The semi-structured interview form consisting of three open-ended questions prepared by the researcher was used to determine their opinions about the Instructional Technologies Material Design course. The interview form was presented to the opinions of two field experts to ensure internal validity in the study. In this context, field experts were asked to determine whether the questions in the interview form were understandable and whether the questions covered the research subject discussed. The questions were re-reviewed based on the feedback received, the necessary corrections were made, and pilot interviews were conducted with eight students who were excluded from sampling. During the pilot interview, whether the questions were understood by the students was tested, and it was concluded that the questions provided the data required for the study, and this interview form was applied to the students. In the interview, 3 questions were posed to pre-service teachers and their answers were analyzed by the content analysis method. Frequency values were used in the analysis of the results. The data obtained as a result of the interviews conducted with the students were evaluated by content analysis. During the process of analysis, the opinions of pre-service teachers were examined based on the categories consisting entirely of their own opinions.

When the answers given to indicate the points to take into account while developing materials in the instructional technologies and material design course are examined, the vast majority of pre-service teachers mostly mentioned 
that the materials to be prepared should first attract students' attention, the prices of the materials to be bought to prepare materials should be affordable and the materials prepared should be durable. Furthermore, pre-service teachers also stated that materials should not be hazardous and should be washable and easy to carry.

With respect to the problems encountered by pre-service teachers while developing materials, the vast majority of pre-service teachers indicated problems, such as the shortage of time during the preparation of materials, inability to find an original idea, difficulty in reflecting their ideas onto the material, expensiveness of materials, differences of opinion within the group, and inability to reflect their ideas onto the material. With respect to pre-service teachers' recommendations for ITMD course to be more efficient, they stated that waste materials should be used, individual homework should be prepared upon request, exhibition should be organized at the end of the term, the materials that would be useful should be sent to schools by obtaining the necessary permissions, and the best prepared material should be rewarded.

As a result of the study, the recommendations for the instructional technologies and materials development course in the faculties of education are as the following; the instructor responsible for the course should explain the content and objective of the course to the students in a clear and understandable language. Then, the instructor and preservice teachers should indicate what the materials to be prepared should include and what the points to take into account are by taking joint decisions. Furthermore, pre-service teachers' request to create a group or to work individually while preparing material should be determined by the joint decision of the student and the instructor. The material designed can be presented to schools so that it can be used again, after obtaining the necessary permissions. Moreover, the materials designed by pre-service teachers can be exhibited at the end of the term to increase their motivation for the course. 